\title{
Glass-reinforced composites based on novel oligoimide-epoxy resin system
}

\author{
H S PATEL and V J SHAH \\ Department of Chemistry, Sardar Patel University, Vallabh Vidyanagar 388 120, India \\ MS received 26 October 1993; revised 2 March 1994
}

\begin{abstract}
A novel matrix resin system, viz. oligoimide-epoxy resin, has been developed to prepare glass-fibre-reinforced composites. Diaminodiphenylmethanebismaleimide-diaminodiphenylmethane (DDMBM-DDM) and p-phenylenebismaieimide-diaminodiphenylmethane (PBM-DDM) oligomers having more $-\mathrm{NH}_{2}$ groups were prepared through Michael addition reaction. These oligoimides were used for curing commercial epoxy resin (i.e. diglycidyl ether of bisphenol A) at $120-140^{\circ} \mathrm{C}$ to fabricate crosslinked oligoimide-epoxy resin glass-fibre-reinforced composites without evolution of byproduct. The fabricated composites (i.e. laminates) were characterized by their chemical resistance and mechanical properties.
\end{abstract}

Keywords. Epoxy resin; oligoimide; glass-fibre-reinforced composites; mechanical properties of composites.

\section{Introduction}

Among the thermally stable polymers, polyimides are widely accepted for their outstanding high-temperature properties. However, their high softening temperature and insoluble nature in most organic solvents make them extremely difficult to process, especially into fibre-reinforced composites. To achieve both the temperature performance of polyimide and the processing ease of epoxy resin, we reported (Patel and Shah 1993) recently the oligoimide-epoxy resin curing system. It was observed that such a novel oligoimide-epoxy resin curing system could be processed easily. This paper reports glass-reinforced composites based on such system and the chemical and mechanical testing of glass-reinforced composites.

\section{Experimental}

\subsection{Materials}

4,4'-Diaminodiphenylmethane and 1,4-phenylenediamine were obtained from SDS Chemicals. $N, N^{\prime}-4,4^{\prime}$-phenylenebismaleimide and $N, N^{\prime}-4,4^{\prime}$-diaminodiphenylmethanebismaleimide were prepared by the method reported earlier (Searl and Arnold 1944; US Patent 1949; Crivello 1976). Commercial epoxy resin, viz. diglycidyl ether of bisphenol A (DGEBA) was obtained from Synpol Products Pvt. Ltd, Ahmedabad, India. The specifications of the epoxy resin are as follows: epoxy equivalent weight $190-210$; viscosity $4-10 \mathrm{P}$ at $25^{\circ} \mathrm{C}$; density at $25^{\circ} \mathrm{C} 1 \cdot 16-1 \cdot 17 \mathrm{~g} / \mathrm{cm}^{3}$. E-type fibreglass woven fabric (polyimide compatible) of $0.25 \mathrm{~mm}$ thickness (Unnati Chemicals, India) of arral weight $270 \mathrm{~g} / \mathrm{m}^{2}$ was used for laminate preparation. 


\subsection{Preparation of oligomers}

$N, N^{\prime}-4,4^{\prime}$-diaminodiphenylmethanebismaleimide-4,4'-diaminodiphenylmethane (DDMBM-DDM) and $N, N^{\prime}-4,4^{\prime}$-phenylenebismaleimide-4,4'-diaminodiphenylmethane (PBM-DDM) oligomers were prepared by the method reported in our earlier communication (Patel and Shah 1993).

\subsection{Composite fabrication}

A suspension mixture of DDMBM-DDM-epoxy resin and PBM-DDM-epoxy resin in tetrahydrofuran was prepared and stirred well for 2 to $5 \mathrm{~min}$. The suspension mixture was applied with a brush on to a $150 \mathrm{~mm} \times 150 \mathrm{~mm}$ polyimide-compatible fibreglass cloth and the solvent was allowed to evaporate. Once dried, the 10-plies of prepreg thus prepared were stacked one on top of another, pressed between steel plates coated with a Teflon film release and compressed in a flat platen press under about 70 psi pressure. The prepreg stack was cured by heating in the press to $120-140^{\circ} \mathrm{C}$ for $12 \mathrm{~h}$. The composite so obtained was cooled to $45^{\circ} \mathrm{C}$ before the pressure was released. Test specimens were made by cutting the composite and machining them to final dimensions. All the chemical, mechanical and electrical tests were conducted according to ASTM or IS methods.

\section{Measurements}

\subsection{Chemical resistance}

The chemical resistance of the composite was measured according to ASTM D543. The sample size was approximately $20 \mathrm{~mm} \times 20 \mathrm{~mm}$. The data are included in table 1 .

\subsection{Mechanical properties}

All the mechanical properties were measured on three individual specimens and the average results have been documented.

3.2a Flexural strength test: The measurement of flexural strength of composites were carried out on a Universal Instron testing machine model number A-74-37 at room temperature according to the testing method of ASTM D770. The crosshead speed was $100 \mathrm{~mm} / \mathrm{min}$.

3.2b Compressive strength test: The compressive strength was measured according to an IS method. The sample size was $12.5 \mathrm{~mm} \times 12.5 \mathrm{~mm}$.

3.2c Impact strength test: According to the testing method of ASTM D256, the measurements were made through an Izod-type impact tester at room temperature.

3.2d Hardness test: The Rockwell hardness strength was measured according to ASTM D785. The sample size was $25 \mathrm{~mm} \times 25 \mathrm{~mm}$. 


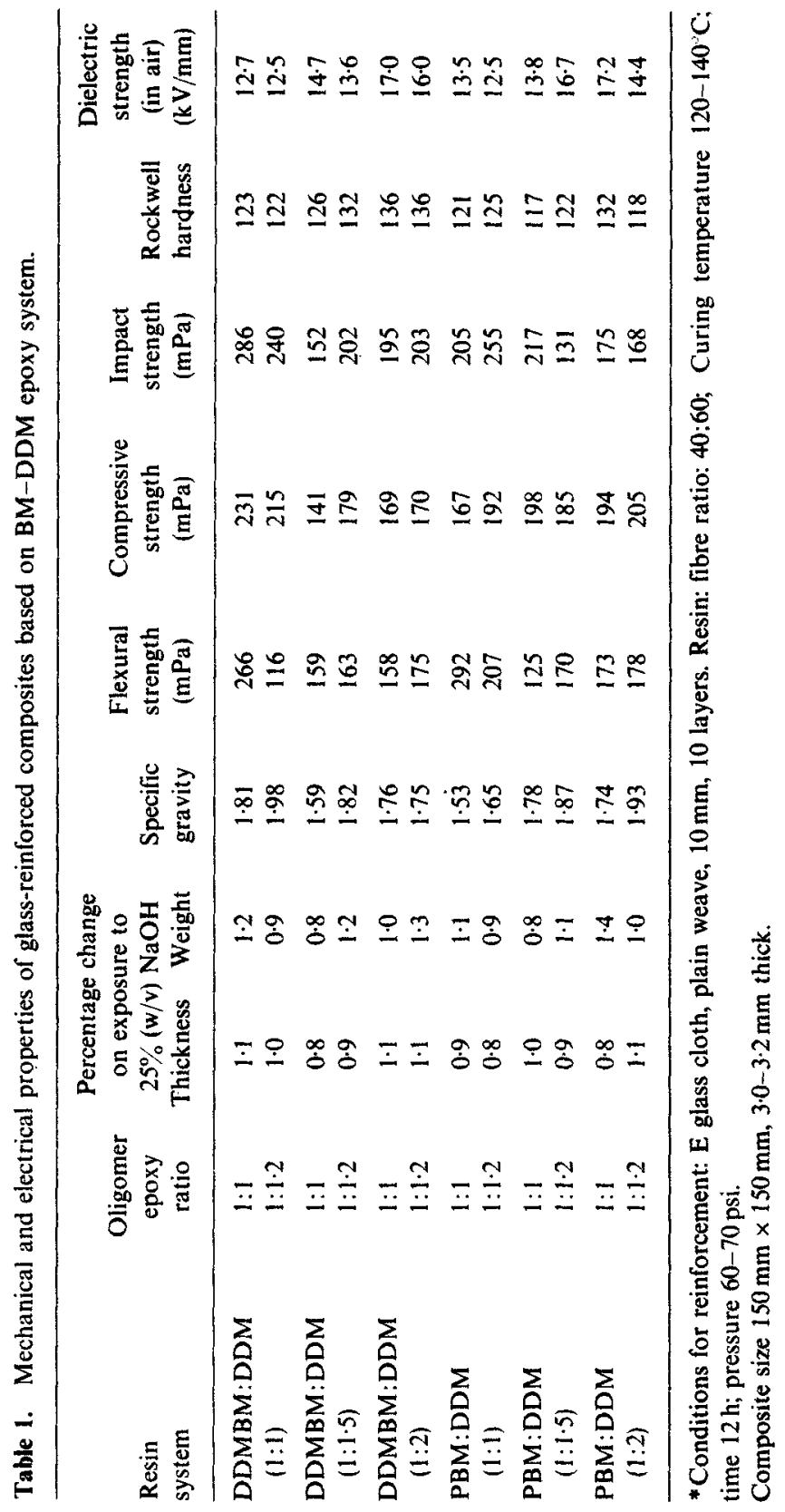


3.2e Electrical testing: Dielectric strength measurements were carried out on a high-voltage tester machine oil test set.

\section{Results and discussion}

The glass-reinforced oligoimide epoxy composites prepared were in the form of dark brown sheets. The specific gravity of these composites is in the range 1.53-1.98 (table 1). Results indicate that there is no appreciable change in the specific gravity with respect to the nature of the bismaleimide and the processing temperature. Chemical resistance studies indicated that the oligoimide glass fibre composites were not affected by immersion in organic solvents (DMF, ketones, alcohols, DMSO, 1,4-dioxane, THF); no change in weight or thickness was observed. It was also noted that concentrated hydrochloric acid $(25 \% \mathrm{v} / \mathrm{v})$ did not affect the composites. However, exposure to concentrated alkali $(25 \% \mathrm{w} / \mathrm{v} \mathrm{NaOH})$ resulted in changes in thickness and weight (table 1). The high chemical resistance of all the composites indicates that the bismaleimide moiety might contribute to high level of crosslinking of epoxy resin with oligoimide during composite fabrication.

As described in an earlier communication the unreinforced cure product obtained from oligoimide and epoxy resin are yellow amorphous powders. They did not melt up to $250^{\circ} \mathrm{C}$ and were insoluble in mineral acids and organic solvents. The film or cast of unreinforced system is too brittle and therefore hardness and other studies are not presented. Since bismaleimides produce a highly crosslinked and brittle polymeric product (Stenzenberger et al 1983) they cannot be applied for preparing advanced composites. Several modifications to the bismaleimide system by addition of vinyl monomers, diamines and elastomers have been examined to improve toughness and mechanical properties (Wilson et al 1990). Addition of epoxy resin to oligoimide having more epoxy-reactive $-\mathrm{NH}_{2}$ groups may increase the toughness of the final product. Such oligoimide epoxy resins and other polymers have only been patented recently (Saito et al 1988) and there is no information regarding the properties of these glass-fibre-reinforced composites. Hence comparison of the mechanical properties of produced glass fibre reinforced composites and those reported about the composites based on bismaleimide resins and epoxy resins individually reveals that the produced laminates have better mechanical properties.

The dielectric strength of all the composites is in the range $12.5-17 \cdot 2 \mathrm{kV} / \mathrm{mm}$. These values are low. This could result in a charred path, over which subsequent discharge could take place more and more readily. Additionally, minute leakage of current may arise from surface contamination.

\section{Conclusions}

Combination of versatile polymers, say epoxy resin and bismaleimide resin, could afford the material for advanced glass-fibre-reinforced composites with better toughness and temperature resistance. 


\section{Acknowledgements}

Help in analysis of laminates by Galaxy India, Ankleswar, is highly appreciated. We are grateful to Prof. M N Patel, Head, Department of Chemistry, for providing the necessary research facilities.

\section{References}

Crivello J V 1976 J. Polym. Sci., Polym. Chem. Ed. 14159

E I Du Pont de Nemours 1949 US Patent 246285

Patel H S and Shah V J 1993 High Perf. Polym. 5145

Patel H S and Shah V J 1993 Macromol. Rep. (in press)

Searl N E and Arnold H W 1944 Chem. Abst. 4344216

Stenzenberger H D, Herzog M, Romer W, Scheiblich R and Reeves N J 1983 Br. Polym. J. 151

Wilson D, Stenzenberger H D and Hergenrother P M 1990 Polyimides (Blackie) pp 79-125

Saito, Eisaku, Yoshimitsu, Tokio, Misawa and Hideto 1988 Japan Kokai Tokkyo Koho JP 63, 130, 635

Saito, Eisaku, Yoshimitsu, Tokio, Misawa and Hideto 1988 Japan Kokai Tokkyo Koho JP 63, 130, 636

Saito, Eisaku, Yoshimitsu, Tokio, Misawa and Hideto 1988 Japan Kokai Tokkyo Koho JP 63, 130, 634 